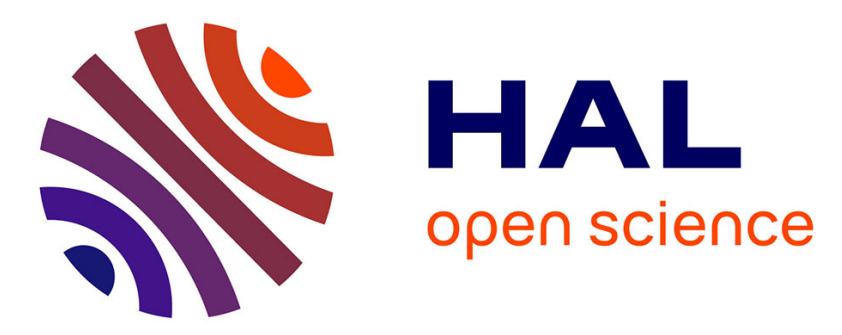

\title{
Influence of the temperature on the mechanical behaviour of filled and unfilled silicone rubbers
}

\author{
Thierry Rey, G. Chagnon, Jean-Benoit Le Cam, Denis Favier
}

\section{To cite this version:}

Thierry Rey, G. Chagnon, Jean-Benoit Le Cam, Denis Favier. Influence of the temperature on the mechanical behaviour of filled and unfilled silicone rubbers. Polymer Testing, 2013, 32 (3), pp.492 501. 10.1016/j.polymertesting.2013.01.008 . hal-01073891

\section{HAL Id: hal-01073891 \\ https://hal.science/hal-01073891}

Submitted on 10 Jan 2019

HAL is a multi-disciplinary open access archive for the deposit and dissemination of scientific research documents, whether they are published or not. The documents may come from teaching and research institutions in France or abroad, or from public or private research centers.
L'archive ouverte pluridisciplinaire HAL, est destinée au dépôt et à la diffusion de documents scientifiques de niveau recherche, publiés ou non, émanant des établissements d'enseignement et de recherche français ou étrangers, des laboratoires publics ou privés. 


\title{
Influence of the temperature on the mechanical behaviour of filled and unfilled silicone rubbers
}

\author{
T. Rey ${ }^{\mathrm{a}}$, G. Chagnon ${ }^{\mathrm{a}, *}$, J.-B. Le Cam ${ }^{\mathrm{b}}$, D. Favier ${ }^{\mathrm{a}}$ \\ a Université de Grenoble, Laboratoire 3SR, Domaine Universitaire, BP53, 38041 Grenoble Cedex 9, France \\ ${ }^{\mathrm{b}}$ Université de Rennes 1, L.A.R.M.A.U.R. - CNRS 6274, Campus de Beaulieu, Bât. 10B, 35042 Rennes Cedex, France
}

\begin{abstract}
This paper investigates the effects of temperature on the mechanical properties of silicone rubbers. First, differential scanning calorimetry tests are performed to determine the crystallization and melting temperatures. Second, mechanical tests are carried out at different temperatures above that of crystallization, up to $150{ }^{\circ} \mathrm{C}$. In this temperature range, the silicone rubbers exhibit entropic behaviour. The neo-hookean model is used to fit the mechanical response. Third, the effects of temperature on the hysteresis, the stress softening and the stress relaxation are studied. Strong differences are observed and discussed.
\end{abstract}

\section{Introduction}

Silicone rubbers are increasingly used in many applications that differ in nature, for instance automotive applications, food storage products, footwear, electronics. This is mainly explained by their easiness of cure and, more generally, of manufacture. Moreover, silicone rubbers do not react with most chemicals, which explains why they are used in many medical applications.

Classically, silicone rubbers are filled with mineral fillers such as silica in order to increase their stiffness. In this case, fillers greatly complicate the mechanical response by inducing numerous phenomena: non-exhaustively, stress softening [1], the Payne effect [2,3] and mechanical hysteresis. Even although mechanical response of filled and unfilled silicone rubbers has already been characterized in the literature at room temperature [4-6], no study investigates the effects of temperature on the mechanical response, while the large variety of applications requires a large range of service temperatures. Moreover, temperature variation

\footnotetext{
* Corresponding author. Tel.: +3347682 70 85; fax: +33 476827043 . E-mail addresses: gregory.chagnon@grenoble-inp.fr, gregory.chagnon@ wanadoo.fr (G. Chagnon).
}

affects the interaction between the fillers and the rubber matrix [7] and, consequently, it is necessary to study both filled and unfilled silicone rubbers.

This paper aims, therefore, at investigating the influence of temperature above that of crystallization on hyperelasticity, stress softening, mechanical hysteresis and stress relaxation. Section 2 presents the materials and the experimental setup. Section 3 gives the results obtained for both materials. The evolution of the various phenomena involved in the deformation of silicone rubbers is discussed in Section 4. Finally, concluding remarks close the paper.

\section{Experimental setup}

This section focuses first on the preparation of the two studied silicone rubbers (Bluestar RTV 141 and RTV 3428), second on the identification of their characteristic temperatures, and third on the mechanical tests performed.

\subsection{Preparation of the silicone rubbers}

The preparation process was similar for the two materials. The first step consisted of blending two liquid 
components, the uncured unfilled silicone RTV 141A (or RTV 3428A for the filled silicone) and $10 / 1 \mathrm{phr}$ in weight of the curing agent RTV 141B for the unfilled silicone (or RTV $3428 \mathrm{~B}$ for the filled silicone). The mixture was then degassed for $30 \mathrm{~min}$ in a vacuum chamber to remove any air bubbles to ensure the material homogeneity. The degassed liquid was injected by means of a medical syringe into a closed mold to guarantee a constant specimen thickness $(2 \mathrm{~mm})$. Finally, the mold was put in an oven at a temperature of $70{ }^{\circ} \mathrm{C}$ for $4 \mathrm{~h}$ to cure the material. This procedure was previously used for the unfilled [4] and filled $[5,6]$ silicone rubbers for studying their mechanical properties at room temperature.

Before testing the temperature effects on the mechanical properties, it is necessary to check that the material is fully cross-linked in order to not superimpose temperature and cross-linking effects. To this end, the materials were heated at different temperatures for different times after curing and then cooled at room temperature. One day rest was imposed before performing the mechanical tests. For each specimen, a uniaxial tensile test was carried out at room temperature. Fig. 1 presents the results obtained for the unfilled silicone in terms of the nominal stress versus the stretch ratio $\lambda$ (defined as the ratio between current and initial lengths). As shown in this figure, the material prepared with the supplier recommendations $\left(4 \mathrm{~h}\right.$ at $\left.70^{\circ} \mathrm{C}\right)$ is not fully cross-linked. Indeed, the specimens heated at $150{ }^{\circ} \mathrm{C}$ for 3 and $6 \mathrm{~h}$ exhibit stiffer behaviour. Moreover, no variation in stiffness is observed after a heating at $150{ }^{\circ} \mathrm{C}$ for $3 \mathrm{~h}$. The microstructure of the material is, therefore, stabilized after such a thermal treatment. Consequently, in the present study, the material was heated $3 \mathrm{~h}$ more at $150^{\circ} \mathrm{C}$. This new procedure ensures that the change in the mechanical response during the test in not due to an increase in cross-linking.

It should be noted that no difference was observed for the filled silicone whatever the applied thermal treatment, meaning that the recommendations of the supplier, i.e. $4 \mathrm{~h}$ at $70^{\circ} \mathrm{C}$, lead to a stabilized microstructure.

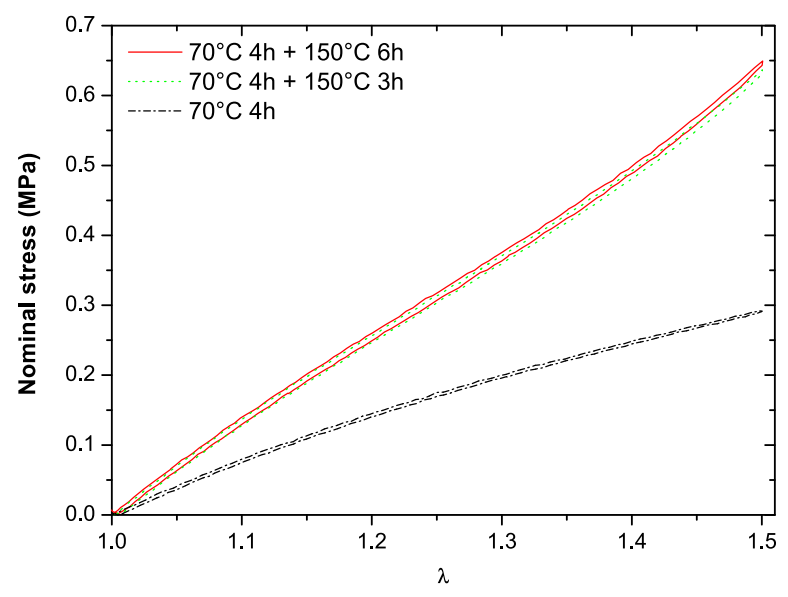

Fig. 1. Influence of curing time on the strain-stress relationship for the unfilled RTV 141 silicone.

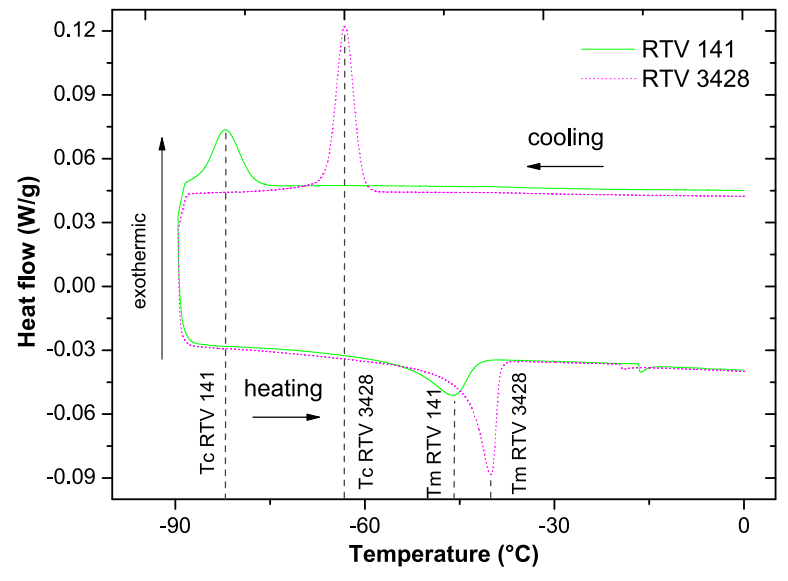

Fig. 2. Heat flow versus temperature measured by means of a DSC for an unfilled and a filled silicone for a temperature cycle from $0{ }^{\circ} \mathrm{C}$ to $-90{ }^{\circ} \mathrm{C}$ and from $-90{ }^{\circ} \mathrm{C}$ to $0{ }^{\circ} \mathrm{C}$. Tc and $\mathrm{Tm}$ are the temperatures where crystallization and crystallites melting occur, respectively.

\subsection{DSC and DMTA analyses}

DSC (Differential Scanning Calorimetry) and DMTA (Dynamic Mechanical and Thermal Analysis) tests were carried out to define the characteristic temperatures of the two silicones, i.e. temperatures of crystallization and melting for a given temperature rate.

The DSC was performed with a TA Q200 differential scanning calorimeter. The cooling rate was set to $2{ }^{\circ} \mathrm{C}$ per minute, and the temperature range between $0{ }^{\circ} \mathrm{C}$ and $-90^{\circ} \mathrm{C}$. Then, heating took place between $-90{ }^{\circ} \mathrm{C}$ and $0{ }^{\circ} \mathrm{C}$ with the same heating rate as previously used. Specimens of 29 and $37 \mathrm{mg}$ weight were used for the unfilled and filled silicones, respectively. Results are presented in Fig. 2. As shown in this figure, an exothermal peak in the heat flowtemperature curve is observed for the two materials during cooling, this corresponds to the crystallization of some of the polymer chains. During heating, an endothermal peak is observed, which corresponds to the crystallites melting. The temperatures for which crystallization and crystallites melting occur are denoted respectively $\mathrm{Tc}$ and $\mathrm{Tm}$ in the following. The values of these characteristic temperatures are reported in Table 1. These tests do not allow us to determine the glass transition temperature for both materials, which occurs at temperature lower than $-90^{\circ} \mathrm{C}$.

Dynamic Mechanical Thermal Analysis (DMTA) tests were carried out by means of a Gabo Eplexor 500N machine with load cell capacity of $25 \mathrm{~N}$. This type of test is classically used to study the amplitude dependence of fillerreinforced rubbers (see for instance [8]). The test consists firstly in cooling with a temperature range between $150{ }^{\circ} \mathrm{C}$

Table 1

Characteristic temperatures for the two silicone rubbers.

\begin{tabular}{lll}
\hline & $\begin{array}{l}\text { Crystallization } \\
\text { temperature }\end{array}$ & $\begin{array}{l}\text { Melting } \\
\text { temperature }\end{array}$ \\
\hline RTV 141 & $-83^{\circ} \mathrm{C}$ & $-47^{\circ} \mathrm{C}$ \\
RTV 3428 & $-66{ }^{\circ} \mathrm{C}$ & $-41^{\circ} \mathrm{C}$ \\
\hline
\end{tabular}



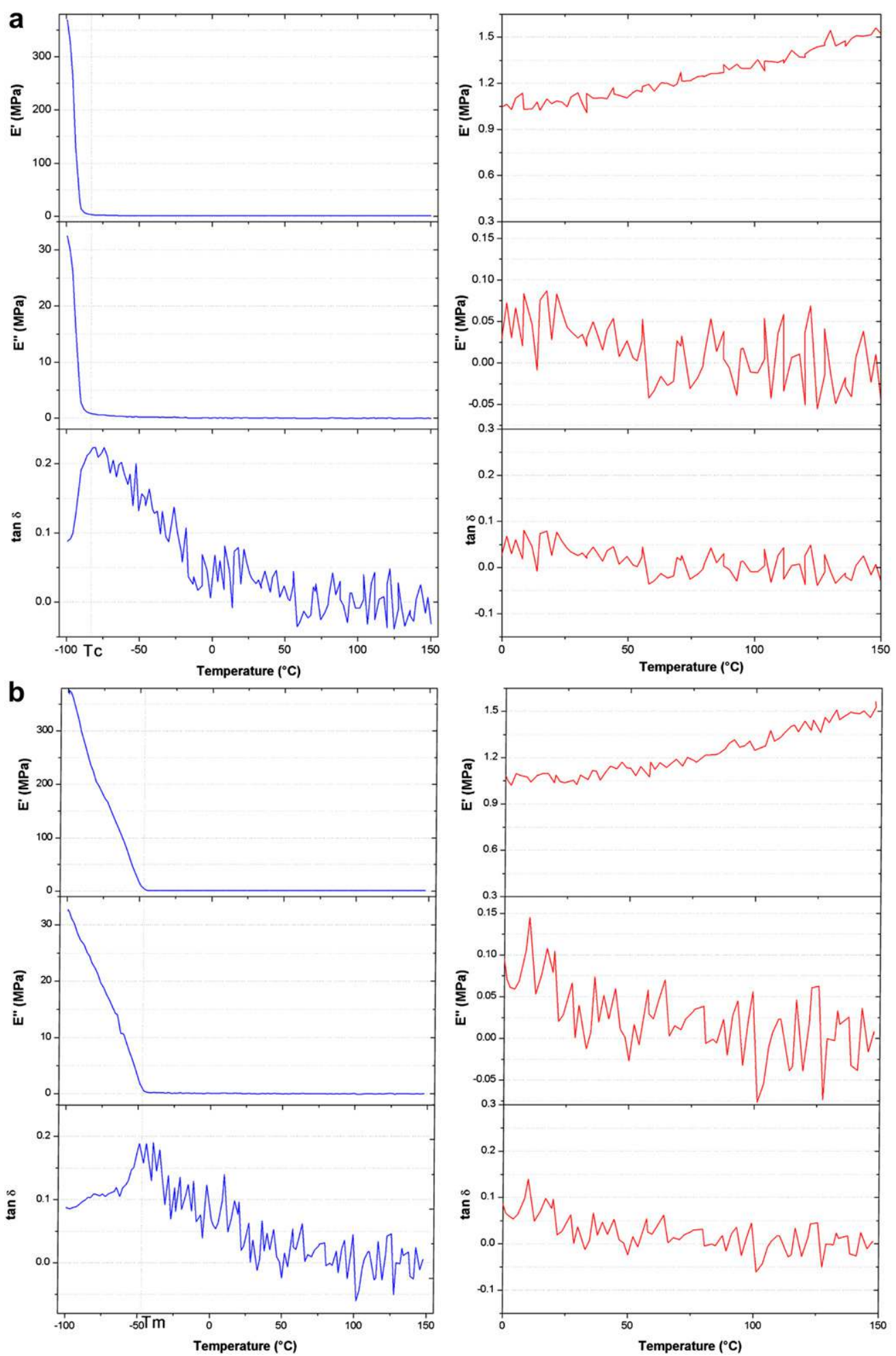

Fig. 3. DMTA realized on an unfilled silicone rubber, the left side presents the results for the whole temperature measurement range (from $-100{ }^{\circ} \mathrm{C}$ to $150{ }^{\circ} \mathrm{C}$ ) while the right side presents a zoom for positive temperatures $\left(0^{\circ} \mathrm{C}, 150^{\circ} \mathrm{C}\right)$ for the cooling (a) and the heating (b). 

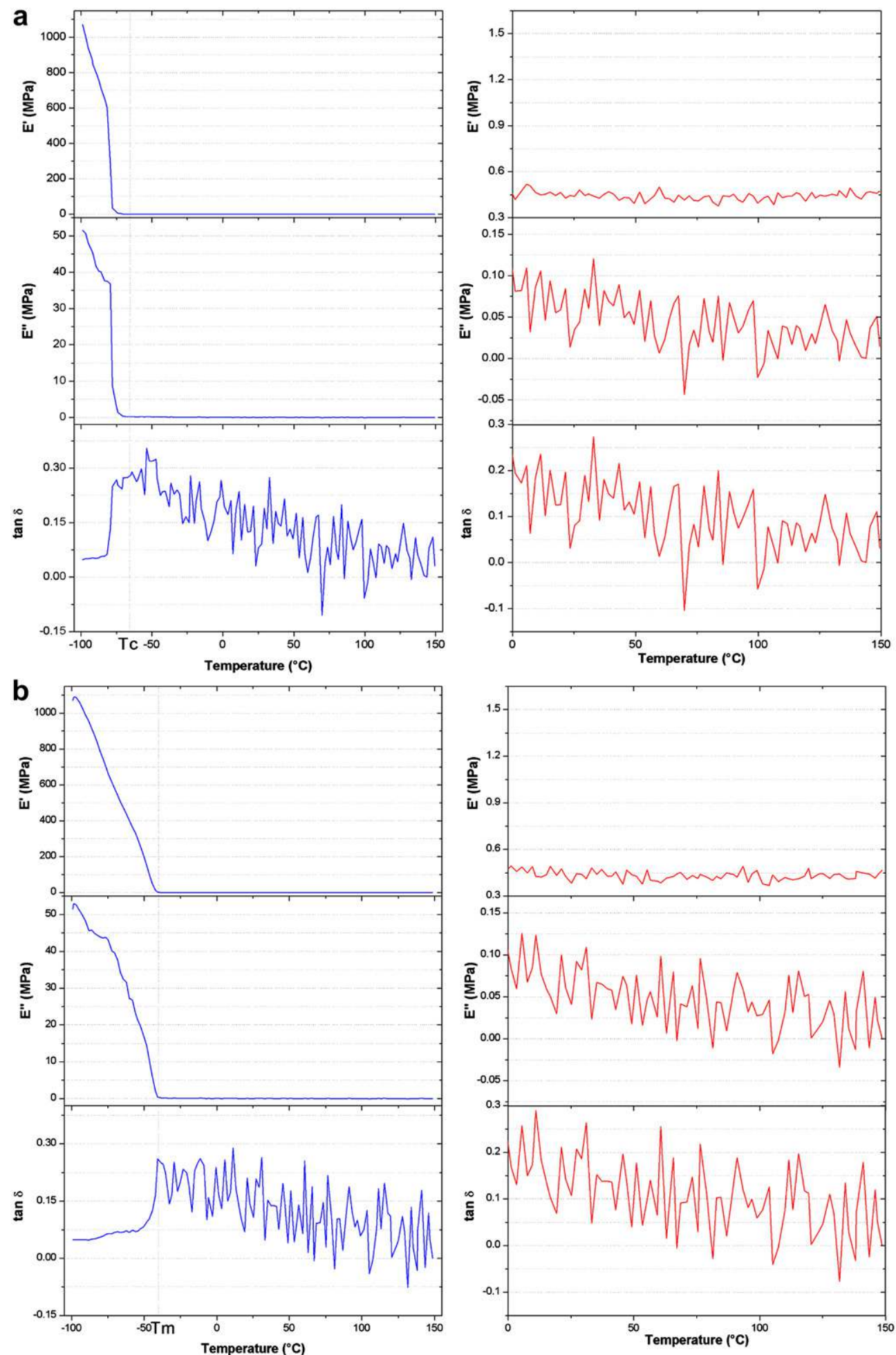

Fig. 4. DMTA realized on a filled silicone rubber, the left side presents the results for the whole temperature measurement range (from $-100{ }^{\circ} \mathrm{C}$ to $150{ }^{\circ} \mathrm{C}$ ) while the right side presents a zoom for positive temperatures $\left(0^{\circ} \mathrm{C}, 150{ }^{\circ} \mathrm{C}\right)$ for the cooling (a) and the heating (b). 
and $-100{ }^{\circ} \mathrm{C}$ at a rate of $2{ }^{\circ} \mathrm{C}$ per minute, and secondly by heating from $-100{ }^{\circ} \mathrm{C}$ to $150{ }^{\circ} \mathrm{C}$ at the same rate. The mean strain applied was equal to $15 \%$ and a double strain amplitude equal to $0.2 \%$ was applied at a frequency of $1 \mathrm{~Hz}$.

Figs. 3 and 4 present the results obtained for the unfilled and the filled silicone, respectively. Results show that both the storage modulus $\left(E^{\prime}\right)$ and the loss modulus $\left(E^{\prime \prime}\right)$ are not affected by temperatures far from $\mathrm{Tc}$ and Tm. During cooling, these two moduli increase sharply close to the Tc for both materials, i.e. from $-80^{\circ} \mathrm{C}$ for the unfilled silicone and from $-60{ }^{\circ} \mathrm{C}$ for the filled one. The results are in good agreement with the literature $([9,10])$. Moreover, these moduli decrease during heating until the temperature reaches Tm. A significant difference is observed between Tc and $\mathrm{Tm}$ for both materials, which confirms the results obtained from the DSC analysis. This difference can be explained by a supercooling effect [11].

The values of $\tan \delta$ are about 0.2 for the filled silicone and about 0.05 for the unfilled one, meaning that the filled material is more viscous than the unfilled, which is in good agreement with previous work in the literature ([12]). Tan $\delta$ slightly decreases for the two materials with decreasing temperature, which highlights that the material viscosity increases by increasing the temperature.

\subsection{Mechanical tests}

As previously shown, the RTV 141 behaves as a purely hyperelastic material at room temperature with a strain at failure close to 100\% [4] whereas the RTV 3428 exhibits stress-softening, hysteresis, stress relaxation and undergoes larger deformations $[5,6]$.

Due to these differences, the mechanical tests performed on both materials were different: for RTV 141, only one uniaxial load-unload cycle at a strain of $50 \%$ was performed, with a strain rate of $1.67 \mathrm{~s}^{-1}$, at temperatures between $-60^{\circ} \mathrm{C}$ and $150^{\circ} \mathrm{C}$. For RTV 3428 , it was necessary to perform several mechanical cycles at increasing deformation. Here, the mechanical cycles were carried out from 25 to $250 \%$ strain, with an increase of $25 \%$ strain between each cycle (see the histogram in Fig. 6). These tests were performed with a strain

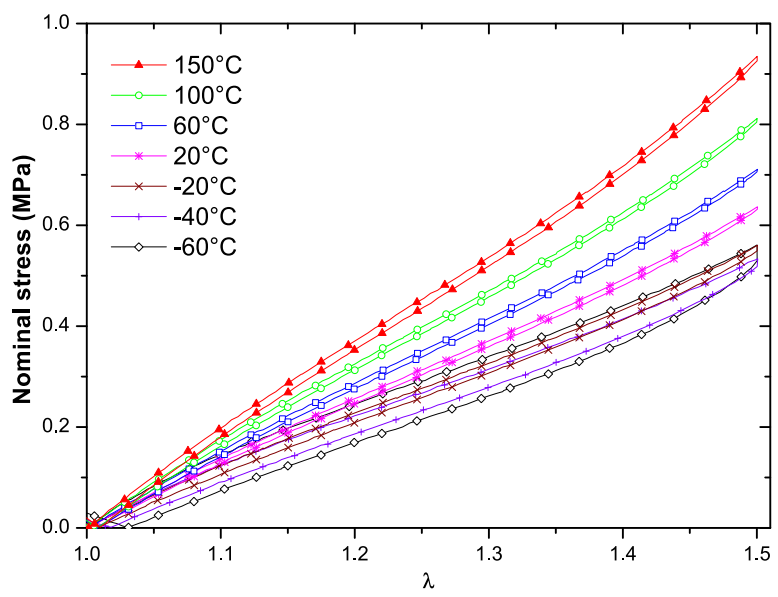

Fig. 5. Cyclic strain-stress tensile test of the unfilled silicone rubber at different temperature. rate equal to $1.67 \mathrm{~s}^{-1}$, between $-40^{\circ} \mathrm{C}$ and $150{ }^{\circ} \mathrm{C}\left(-60{ }^{\circ} \mathrm{C}\right.$ is close to Tc for this material).

A second type of mechanical test was then performed, which corresponds to relaxation tests. For the unfilled silicone, a maximum strain equal to $50 \%$ was applied with a strain rate set to $1.67 \mathrm{~s}^{-1}$. For the filled silicone, one mechanical cycle was beforehand performed at a maximum strain equal to $250 \%$ in order to remove the stress softening of the first cycle and to focus only on the relaxation properties [13-15]. After a rest time greater than $4 \mathrm{~h}$, which ensures recovery of the viscoelastic properties, a relaxation test was carried out by applying a $150 \%$ maximum strain with a strain rate equal to $1.67 \mathrm{~s}^{-1}$.

\section{Tests results}

Fig. 5 presents the results of uniaxial tensile tests for the unfilled silicone. The stiffness of the material increases with temperature, except at $-60^{\circ} \mathrm{C}$. These curves highlight the entropic behaviour of the unfilled silicone rubber for temperatures far from Tc. For temperature close to Tc, typically $-60{ }^{\circ} \mathrm{C}$, the material behaviour remains entropic, but crystallites form in the bulk material and act as fillers $[11,16]$. Consequently, the material stiffness increases, meaning that the effect of crystallization on the mechanical response of the material is of the first order compared to that of entropy variation. It should be noted that the change in the preparation process, more especially the fact that the material is fully cross-linked in the present study, explains the differences from the results obtained by Meunier et al. [4].

Fig. 6 presents the results obtained for the filled silicone. First, a significant difference between the load and unload curves is observed, which forms a hysteresis loop. Moreover, a difference of stiffness is observed between the first and the second loads at a same strain level. This softening is one of the features of the Mullins effect [1]. Second, for temperatures lower than $0{ }^{\circ} \mathrm{C}$, the material becomes stiffer when the temperature is close to Tc. For temperatures greater than $0^{\circ} \mathrm{C}$, despite a loss of material stiffness due to the viscosity when the temperature increases, the material becomes stiffer, meaning that the entropic effect is more significant than the viscous one. It can be noted that the test performed at $150{ }^{\circ} \mathrm{C}$ is not completed as the specimen fails at about $200 \%$ strain.

Fig. 7 presents the results of the relaxation tests for the unfilled silicone. In this figure, the nominal stress is normalized to the maximum nominal stress reached during the test (the start point of the stress relaxation). The values of the maximum nominal stress measured are reported in Table 2. Each curve represents a monotonic decreasing function of time. Without considering the curve obtained at $-20^{\circ} \mathrm{C}$, the higher the temperature, the lower the stress relaxation. Results obtained at $-20{ }^{\circ} \mathrm{C}$ are not clearly explained and require further investigation.

Fig. 8 presents the results obtained for the filled silicone, Table 2 gives the values of the maximum nominal stress measured. Once again, the relaxation decreases with increasing temperature. These results are similar to those proposed by Laurent et al. [17] and Vandenbroucke [18] on other rubber-like materials. No result is available at $150{ }^{\circ} \mathrm{C}$, due to the fact that the material fails during the preconditioning step at $250 \%$. 


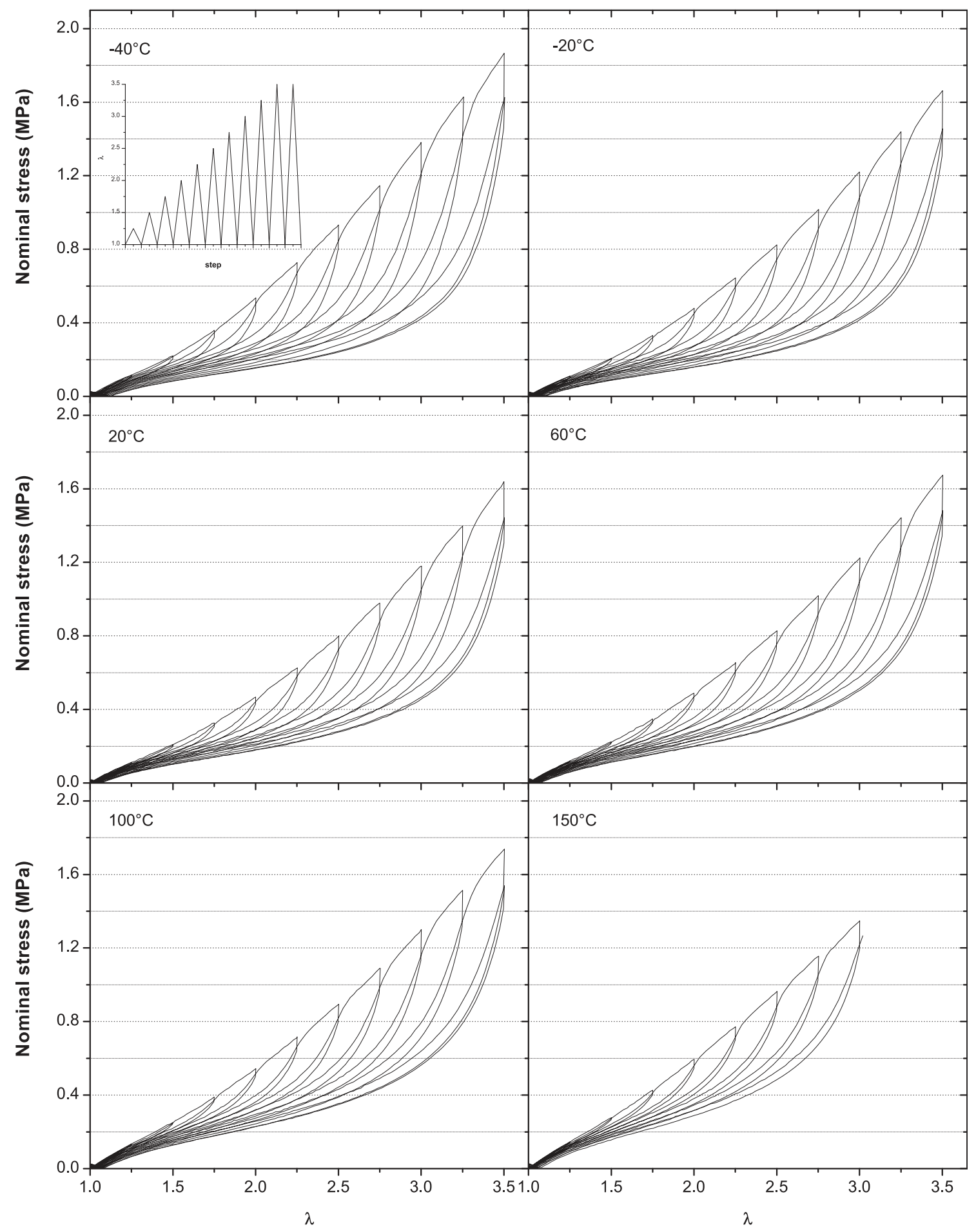

Fig. 6. Tensile strain-stress curves at different temperatures for the filled silicone rubber. 


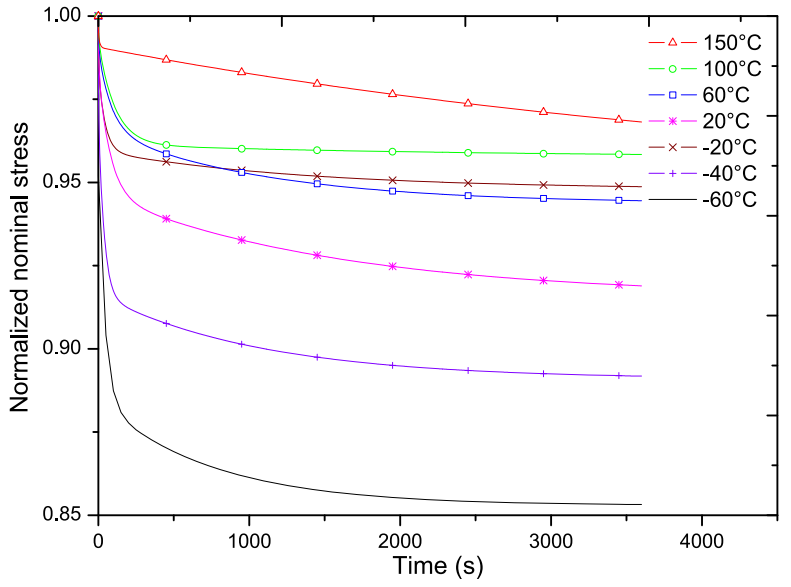

Fig. 7. Stress relaxation responses for the unfilled silicone.

\section{Discussion}

In this section, the relation between temperature and strain on the material behaviour is first discussed by considering the neo-hookean model.

Then, the effects of the temperature on the Mullins effect and the mechanical hysteresis are successively investigated.

\subsection{Modeling of temperature dependency of the mechanical response}

The neo-hookean model [19] was used to predict the experimental results previously presented. In this case, the evolution of nominal stress $\pi$ (in MPa) is written with the stretch $\lambda$ and the temperature $T$ (in $\mathrm{K}$ ) as follows:

$\pi=n k T\left(\lambda-1 / \lambda^{2}\right)$

where $n$ is the density of macromolecular chains by volume unit $\left(\mathrm{mm}^{-3}\right)$ and $k$ is the Boltzmann constant $\left(\mathrm{J} \mathrm{K}^{-1}\right)$. The parameter $n k$ was fitted for the unfilled silicone for a temperature of $20{ }^{\circ} \mathrm{C}$ and a strain level lower than $25 \%$. The value of $n k$ was found to be equal to $1.29 \times 10^{-3} \mathrm{~J} \mathrm{~K}^{-1}$. Then, this value was used to plot the curves at each temperature. Fig. 9 shows the curves obtained. This figure shows that the neo-hookean model satisfactorily predicts the experimental results for $-20,20$ and $60{ }^{\circ} \mathrm{C}$. However, the model does not predict correctly the material behaviour for temperatures equal to $-40{ }^{\circ} \mathrm{C}$ and $100{ }^{\circ} \mathrm{C}$ and even less at $150{ }^{\circ} \mathrm{C}$. This seems to indicate that the neo-hookean model gives a good approximation of the material behaviour in a range of temperature between $-20^{\circ} \mathrm{C}$ and $60^{\circ} \mathrm{C}$ (i.e. room temperature $\pm 40^{\circ} \mathrm{C}$ ) if the model parameter is fitted from

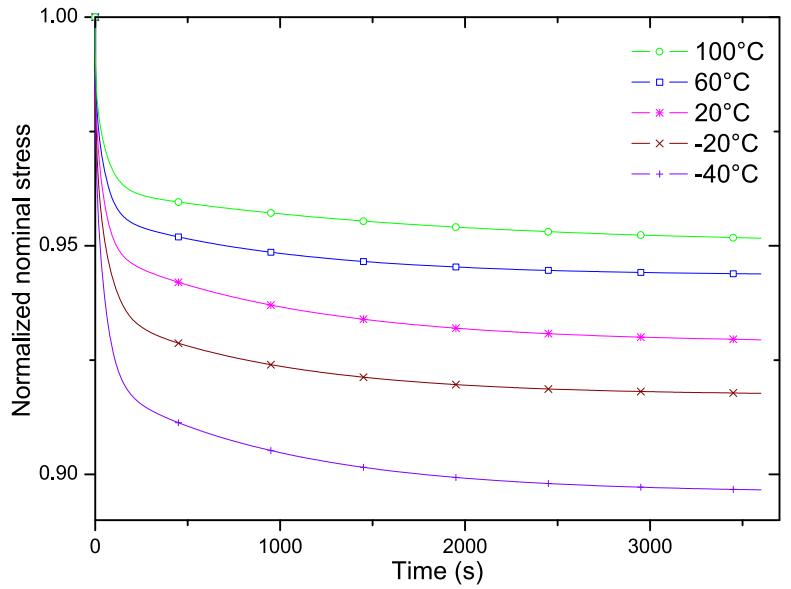

Fig. 8. Stress relaxation responses for the filled silicone.

tests at room temperature, $20{ }^{\circ} \mathrm{C}$ in the present study. The poor prediction of the model for $-40{ }^{\circ} \mathrm{C}$ is due to the fact that the material stiffness is increasing as the appearance of crystallites begins, and the value of $n k$ previously calculated is no longer correct.

The same model was used to fit the experimental results of the filled silicone. The parameter $n k$ was fitted on the experimental curve at $20^{\circ} \mathrm{C}$, and was used to plot the curves for all the other temperatures. For the filled material, $n k$ is equal to $5.1 \times 10^{-4} \mathrm{~J} \mathrm{~K}^{-1}$ Fig. 10 gives the results obtained. This figure highlights that the neo-hookean model predicts approximately the evolution in the mechanical response with temperature for this material. The evolution of the mechanical response is underestimated for -20 and $-40{ }^{\circ} \mathrm{C}$ whereas it is better estimated for 60,100 and $150{ }^{\circ} \mathrm{C}$. This is due to the fact that the neo-hookean model accounts for the macromolecular network elasticity, but not the matrix-filler interactions. More elaborate models could be used, as done for example by Korochkina et al. [20], but it is not the objective of the present study.

\subsection{Mullins effect}

The unfilled silicone is not subject to stress softening, which is the reason why this analysis only deals with the filled silicone. As classically reported in the literature, our results show that the filled silicone exhibits stress softening, which is mainly observed between the first and second loads [5]. It has often been considered as a damage phenomenon [21-24].

In order to evaluate the stress-softening, several methods can be used, among them that by Stevenson et al.

Table 2

Maximum nominal stress measured during the stress relaxation tests.

\begin{tabular}{|c|c|c|c|c|c|c|c|}
\hline Temperature & $-60^{\circ} \mathrm{C}$ & $-40^{\circ} \mathrm{C}$ & $-20^{\circ} \mathrm{C}$ & $20^{\circ} \mathrm{C}$ & $60^{\circ} \mathrm{C}$ & $100{ }^{\circ} \mathrm{C}$ & $150{ }^{\circ} \mathrm{C}$ \\
\hline Maximum nominal stress $>$ measured for the $>$ unfilled silicone $(\mathrm{MPa})$ & 0.57 & 0.55 & 0.57 & 0.65 & 0.72 & 0.82 & 0.94 \\
\hline Maximum nominal stress $>$ measured for the filled $>$ silicone $(\mathrm{MPa})$ & & 0.31 & 0.3 & 0.33 & 0.37 & 0.41 & \\
\hline
\end{tabular}



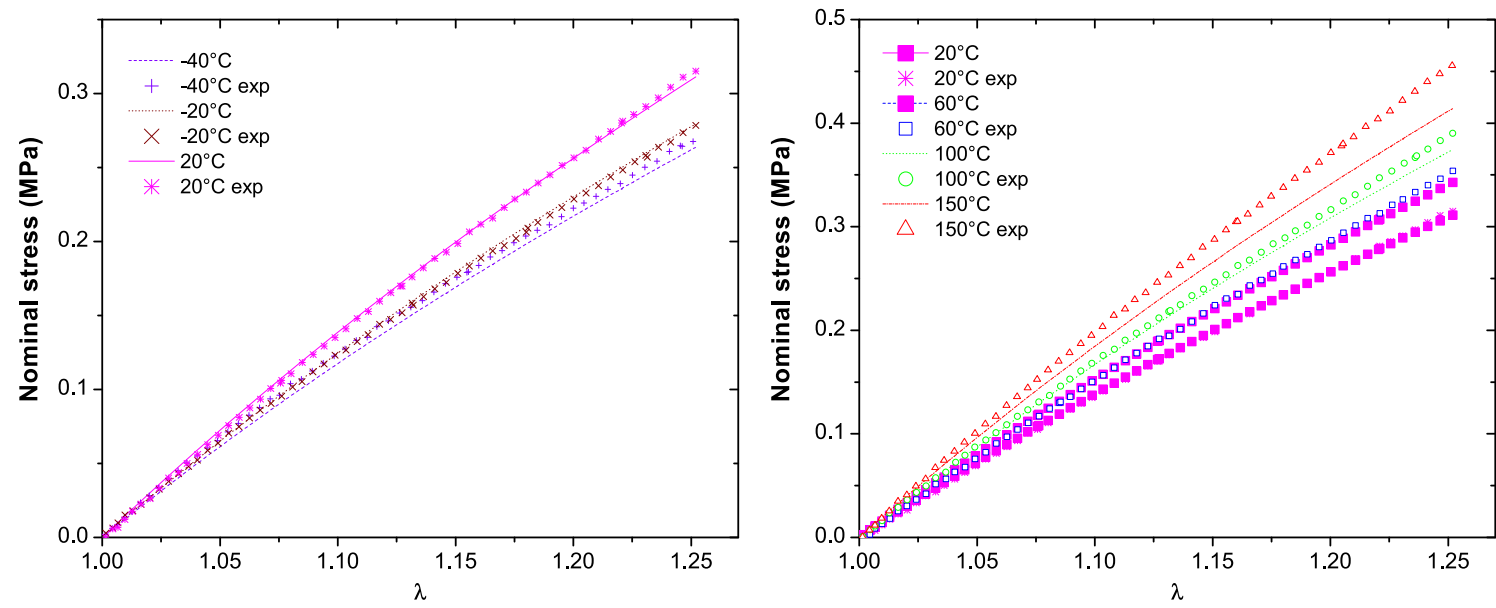

Fig. 9. Comparison between neo-hookean model and experimental results for the unfilled silicone rubber.

[25]. This method consists of calculating the ratio between the energies brought during load and unload. In the present study, we calculated the ratio between the energies brought during second (W2L) and first (W1L) loads. This method, which was previously proposed in [5], allows us to remove the effect of hysteresis from the calculation. The measurement of energy is defined by:

$W=\int_{\overline{\bar{F}}} \overline{\bar{\pi}}: d \overline{\bar{F}}$

where $\overline{\bar{\pi}}$ is the nominal stress tensor and $\overline{\bar{F}}$ is the deformation gradient tensor.

Fig. 11 presents the evolution of this ratio for different maximum strain levels from 25 to $250 \%$ for a temperature range between $-40{ }^{\circ} \mathrm{C}$ and $150{ }^{\circ} \mathrm{C}$. It appears that the energy loss increases with deformation whatever the temperature. The curves corresponding to 60,100 and $150{ }^{\circ} \mathrm{C}$ are confounded, meaning that above $60^{\circ} \mathrm{C}$ the stress softening evolution is not greatly dependent on temperature, whereas below $60{ }^{\circ} \mathrm{C}$, the lower the temperature, the

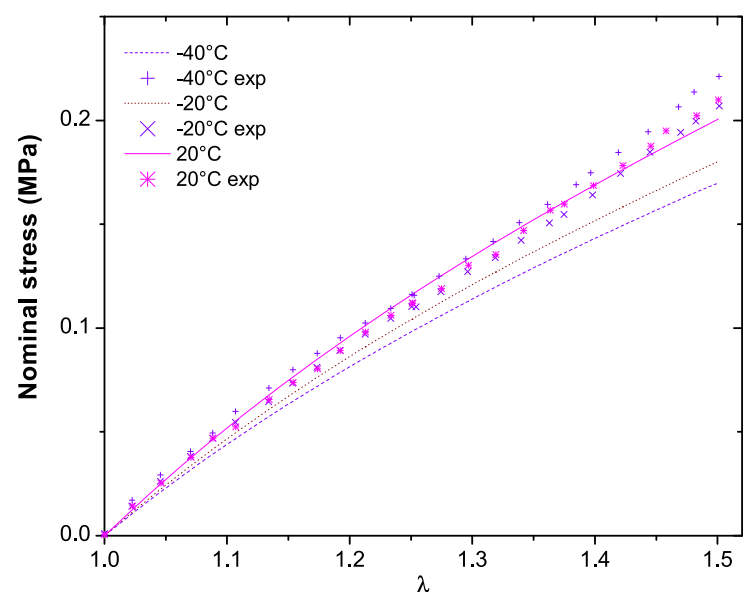

higher the stress-softening. This means that the macromolecular network is more sensitive to stress softening at low temperatures.

\subsection{The mechanical hysteresis}

In unfilled silicone, mechanical hysteresis is only observed for a maximum strain equal to $50 \%$. For lower strain levels, it is not detected. Fig. 12 gives the evolution of the hysteresis area between load W1L and unload W1U (W1L-W1U) versus the temperature for this maximum strain level. As shown in this figure, the hysteresis loop area is quasi-constant for temperatures above $0{ }^{\circ} \mathrm{C}$. However, for temperatures below $0{ }^{\circ} \mathrm{C}$, the hysteresis loop area greatly increases until the temperature reaches Tc.

For the filled silicone rubber, the hysteresis loop is observed for strains from 25 to $250 \%$. Fig. 13 presents the corresponding hysteresis loop area versus the strain. As shown in this figure, the hysteresis loop area increases with the strain and seems to be not affected by the temperature. It should be noted that the area slightly increases with temperatures that tend to Tc.

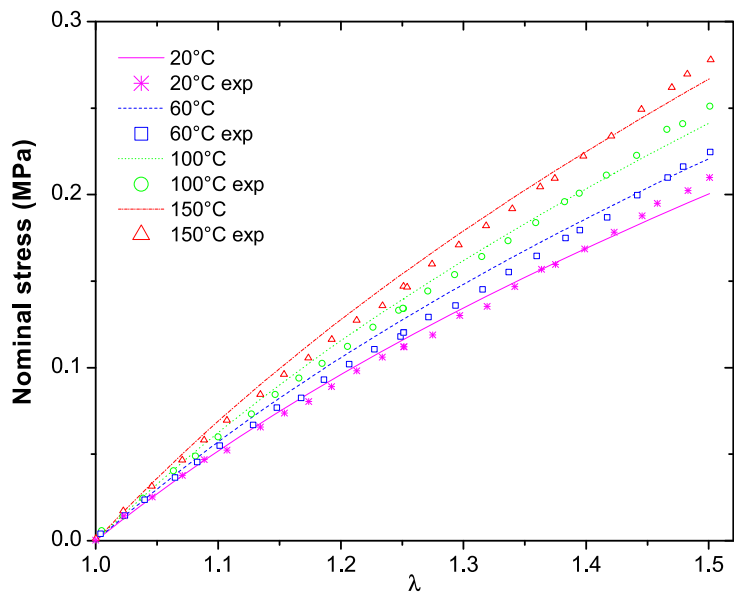

Fig. 10. Comparison between neo-hookean model and experimental results for the filled silicone rubber 


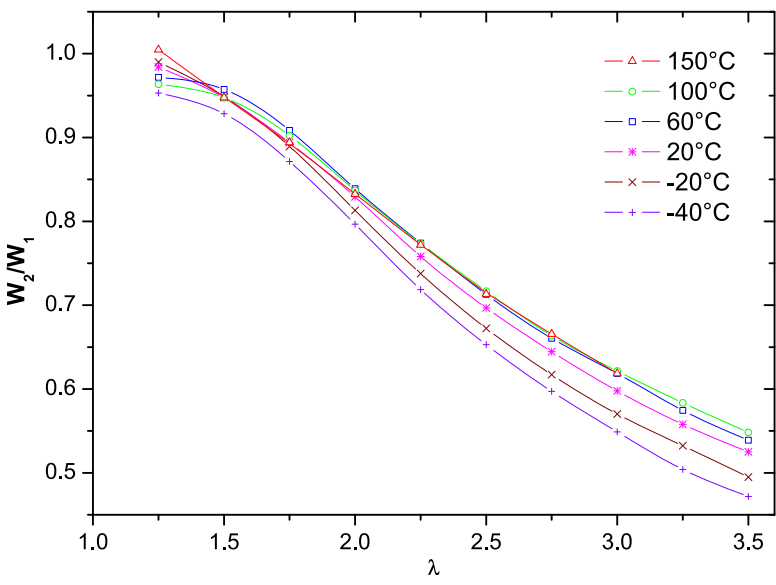

Fig. 11. Evolution of the energy ratio between first and second loads versus the maximum elongation for different temperatures.

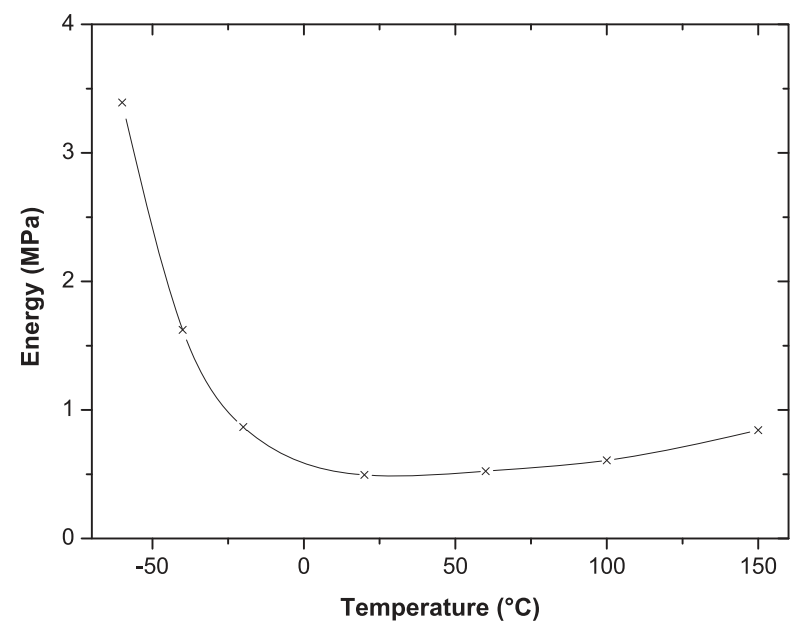

Fig. 12. Energy corresponding to the hysteresis loop for the unfilled silicone at different temperatures for a strain of $50 \%$.

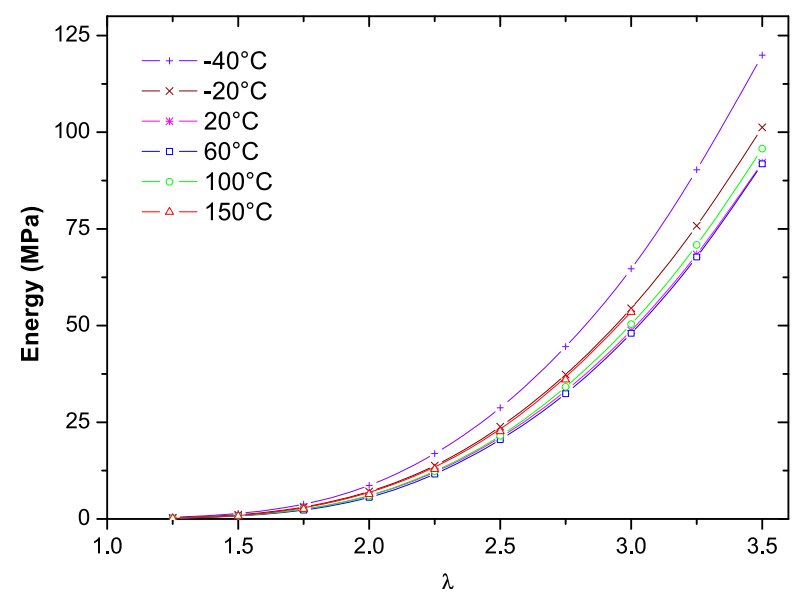

Fig. 13. Energy corresponding to the hysteresis loop during the first cycle for the filled silicone at different temperatures.

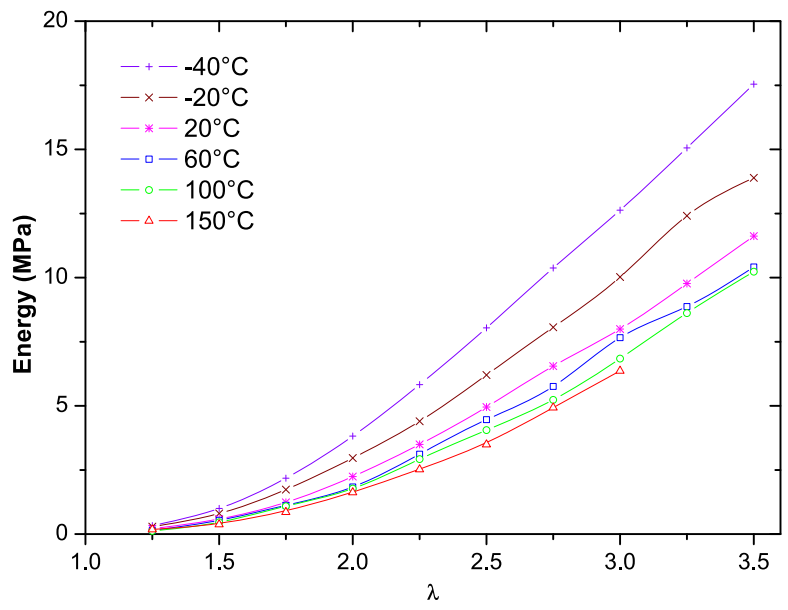

Fig. 14. Energy corresponding to the hysteresis loop during the second cycle (i.e. after stress softening) for the filled silicone at different temperatures.

Fig. 14 gives the hysteresis between the second load and unload (W2L-W1U). The evolution of the hysteresis loop area versus the strain is similar as that obtained previously for the first load cycles. The difference lies first in the size of the hysteresis loops, which are five times smaller than for the first load cycles, and second in the fact that the higher the temperature, the smaller the hysteresis loop area. This is in good agreement with the fact that once the Mullins effect is removed from the mechanical response, the hysteresis loop is only due to viscosity.

The fact that hysteresis loops obtained in the first cycles are not influenced by the temperature means that the Mullins effect is mainly responsible. Indeed, contrarily to hysteresis due to viscosity (see Fig. 14), Mullins effect observed in filled silicone rubber is not significantly dependent on the temperature.

\section{Conclusions}

This study investigated the effects of temperature on the mechanical properties of filled and unfilled silicone rubbers, especially on hyperelasticity, mechanical hysteresis, stress softening and stress relaxation. Results show that the stabilized behaviour of silicone rubbers depends quasi-linearly on the temperature. This is not true for the other phenomena. Typically in filled silicone rubber, the magnitude of hysteresis, stress relaxation and stress softening decrease by increasing the temperature. Moreover, up to $60{ }^{\circ} \mathrm{C}$, the temperature does not alter the stress softening. For these reasons, the modeling of phenomena involved in the deformation of rubbers should account for the non-linear dependence of these phenomena on the temperature. Consequently, this study opens a new way for the modeling of classical phenomena observed in rubbers, more particularly for the modeling of the Mullins effect, whose softening function should depend on a decreasing and asymptotic function of the temperature. Further work in this field is currently being carried out by the authors. 


\section{Acknowledgements}

The authors would like to thank the French ANR for supporting this work through the project ANiM ("Architectured NiTi Materials").

\section{References}

[1] L. Mullins, Effect of stretching on the properties of rubber, Rubber Chem. Technol. 21 (1948) 281-300.

[2] W.P. Fletcher, A.N. Gent, Non-linearity in the dynamic properties of vulcanised rubber compounds, Trans. Inst. Rubber Ind. 29 (1953) 266-280.

[3] A.R. Payne, The dynamic properties of carbon black-loaded natural rubber vulcanizates. Part I, J. Appl. Polym. Sci. 6 (1962) 57-63.

[4] L. Meunier, G. Chagnon, D. Favier, L. Orgéas, P. Vacher, Mechanical experimental characterisation and numerical modelling of an unfilled silicone rubber, Polym. Test. 27 (2008) 765-777.

[5] G. Machado, G. Chagnon, D. Favier, Analysis of the isotropic models of the Mullins effect based on filled silicone rubber experimental results, Mech. Mater. 42 (2010) 841-851.

[6] G. Machado, G. Chagnon, D. Favier, Induced anisotropy by the Mullins effect in filled silicone rubber, Mech. Mater. 50 (2012) $70-80$.

[7] R.N. Rothon, Particulate Fillers for Polymers, Smithers Rapra Technology, UK, 2001

[8] M. Rendek, A. Lion, Amplitude dependence of filler-reinforced rubber: experiments, constitutive modelling and FEM - implementation, Int. J. Solids Struct. 47 (2010) 2918-2936.

[9] S.O. Rogero, J.S. Sousa, D. Alario Jr., L. Lopérgolo, A.B. Lugao, Silicone crosslinked by ionizing radiation as potential polymeric matrix for drug delivery, Nucl. Instrum. Methods Phys. Res. Sect. B 236 (2005) 521-525.

[10] K. Stathi, P.A. Tarantili, G. Polyzois, The effect of accelerated ageing on performance properties of addition type silicone biomaterials, J. Mater. Sci. Mater. Med. 21 (2010) 1403-1411.

[11] S. Trabelsi, P.A. Albouy, J. Rault, Crystallization and melting processes in vulcanized stretched natural rubber, Macromolecules 36 (2003) 7624-7639.
[12] S.-S. Hou, Y.-P. Chung, C.-K. Chan, P.-L. Kuo, Function and performance of silicone copolymer. Part IV. Curing behaviour and characterization of epoxy-siloxane copolymers blended with diglycidyl ether of bisphenol-A, Polymer 41 (1999) 3263-3272.

[13] J.S. Bergström, M.C. Boyce, Constitutive modeling of the large strain time-dependent behaviour of elastomers, J. Mech. Phys. Solids 46 (5) (1998) 931-954.

[14] A. Lion, A physically based method to represent the thermomechanical behaviour of elastomers, Acta Mech. 123 (1996) 1-25.

[15] O.H. Yeoh, Characterization of elastic properties of carbon black filled rubber vulcanizates, Rubber Chem. Technol. 63 (1990) 792-805.

[16] P.J. Flory, Thermodynamics of crystallization in high polymers. I. Crystallization induced by stretching, J. Chem. Phys. 15 (1947) 397-408.

[17] H. Laurent, A. Vandenbroucke, S. Couedo, G. Rio, An hyper-viscohysteretic model for elastomeric behaviour under low and high temperatures: experimental and numerical investigations, in: Constitutive Models for Rubber V, 2008, pp. 47-52.

[18] A. Vandenbroucke, Etude du comportement mécanique pour différentes températures d'un élastomère: caractérisation expérimentale et numérique, PhD, Université de Bretagne Sud, 2010.

[19] L.R.J. Treloar, The elasticity of a network of long chain molecules I and II, Trans. Faraday Soc. 39, 1943, pp. 36-64 and 241-246.

[20] T.V. Korochkina, E.H. Jewell, T.C. Claypole, D.T. Gethin, Experimental and numerical investigation into nonlinear deformation of silicone rubber pads during ink transfer process, Polym. Test. 27 (2008) 778-791.

[21] M.F. Beatty, S. Krishnaswamy, A theory of stress-softening in incompressible isotropic materials, J. Mech. Phys. Solids 48 (2000) 1931-1965.

[22] G. Chagnon, E. Verron, L. Gornet, G. Marckmann, P. Charrier, On the relevance of Continuum Damage Mechanics as applied to the Mullins effect in elastomers, J. Mech. Phys. Solids 52 (2004) 1627-1650.

[23] A. DeSimone, J.J. Marigo, L. Teresi, A damage mechanics approach to stress softening and its application to rubber, Eur. J. Mech. A/Solids 20 (2001) 873-892.

[24] J. Diani, M. Brieu, P. Gilormini, Observation and modeling of the anisotropic visco-hyperelastic behaviour of a rubberlike material, Int. J. Solids Struct. 43 (2006) 3044-3056.

[25] I. Stevenson, L. David, C. Gauthier, L. Arambourg, J. Davenas, $\mathrm{G}$. Vigier, Influence of $\mathrm{SiO}_{2}$ fillers on the irradiation ageing of silicone rubbers, Polymer 42 (2001) 9287-9292. 